\title{
Fixed point solutions of variational inequalities for a semigroup of asymptotically nonexpansive mappings in Banach spaces
}

\author{
Pongsakorn Sunthrayuth and Poom Kumam*
}

\section{"Correspondence:}

poom.kum@kmutt.ac.th

Department of Mathematics,

Faculty of Science, King Mongkut's

University of Technology Thonburi

(KMUTT), Bangmod, Bangkok,

10140, Thailand

\begin{abstract}
The purpose of this article is to introduce two iterative algorithms for finding a common fixed point of a semigroup of asymptotically nonexpansive mappings which is a unique solution of some variational inequality. We provide two algorithms, one implicit and another explicit, from which strong convergence theorems are obtained in a uniformly convex Banach space, which admits a weakly continuous duality mapping. The results in this article improve and extend the recent ones announced by Li et al. (Nonlinear Anal. 70:3065-3071, 2009), Zegeye et al. (Math. Comput. Model. 54:2077-2086, 2011) and many others.
\end{abstract}

MSC: $47 \mathrm{H} 05 ; 47 \mathrm{H} 09 ; 47 \mathrm{H} 20 ; 47 \mathrm{~J} 25$

Keywords: iterative approximation method; common fixed point; semigroup of asymptotically nonexpansive mapping; strong convergence theorem; uniformly convex Banach space

\section{Introduction}

Throughout this paper, we denote by $\mathbb{N}$ and $\mathbb{R}^{+}$the set of all positive integers and all positive real numbers, respectively. Let $X$ be a real Banach space. A mapping $T: X \rightarrow X$ is said to be nonexpansive if

$$
\|T x-T y\| \leq\|x-y\|, \quad \forall x, y \in X,
$$

and $T$ is asymptotically nonexpansive (see [1]) if there exists a sequence $\left\{k_{n}\right\}$ of positive real numbers with $\lim _{n \rightarrow \infty} k_{n}=1$ such that

$$
\left\|T^{n} x-T^{n} y\right\| \leq k_{n}\|x-y\|, \quad \forall n \geq 1 \text { and } \forall x, y \in X .
$$

We denote by $\operatorname{Fix}(T)$ the set of fixed points of $T$, i.e., $\operatorname{Fix}(T)=\{x \in X: x=T x\}$.

Recall that a self-mapping $f: X \longrightarrow X$ is a contraction if there exists a constant $\alpha \in(0,1)$ such that

$$
\|f(x)-f(y)\| \leq \alpha\|x-y\|, \quad \forall x, y \in X .
$$

A one-parameter family $\mathcal{S}=\left\{T(t): t \in \mathbb{R}^{+}\right\}$of $X$ into itself is said to be a strongly continuous semigroup of Lipschitzian mappings if the following conditions are satisfied:

(C) 2012 Sunthrayuth and Kumam; licensee Springer. This is an Open Access article distributed under the terms of the Creative Commons Attribution License (http://creativecommons.org/licenses/by/2.0), which permits unrestricted use, distribution, and reproduction in any medium, provided the original work is properly cited. 
(i) $T(0) x=x$ for all $x \in X$;

(ii) $T(s+t)=T(s) \circ T(t)$ for all $s, t \in \mathbb{R}^{+}$;

(iii) for each $x \in X$ the mapping $T(\cdot) x$ from $\mathbb{R}^{+}$into $X$ is continuous;

(iv) for each $t>0$, there exists a bounded measurable function $L_{t}:(0, \infty) \longrightarrow[0, \infty)$ such that

$$
\|T(t) x-T(t) y\| \leq L_{t}\|x-y\|, \quad \forall x, y \in X
$$

A strongly continuous semigroup of Lipschitzian mappings $\mathcal{S}$ is called strongly continuous semigroup of nonexpansive mappings if $L_{t} \equiv 1$ for all $t>0$ and strongly continuous semigroup of asymptotically nonexpansive mappings if lim $\sup _{t \rightarrow \infty} L_{t} \leq 1$. Note that for asymptotically nonexpansive semigroup $\mathcal{S}$, we can always assume that the Lipschitzian constant $\left\{L_{t}\right\}_{t>0}$ is such that $L_{t} \geq 1$ for each $t>0, L_{t}$ is nonincreasing in $t$ and $\lim _{t \rightarrow \infty} L_{t}=1$; otherwise, we replace $L_{t}$ for each $t>0$ with $\bar{L}_{t}:=\max \left\{\sup _{s \geq t} L_{s}, 1\right\} . \mathcal{S}$ is said to have a fixed point if there exists $x_{0} \in X$ such that $T(t) x_{0}=x_{0}$ for all $t \geq 0$. We denote by $\operatorname{Fix}(\mathcal{S})$ the set of fixed points of $\mathcal{S}$, i.e., $\operatorname{Fix}(\mathcal{S})=\bigcap_{t \geq 0} \operatorname{Fix}(T(t))$ (for more details, see [2-4]).

A continuous operator of the semigroup $\mathcal{S}=\left\{T(t): t \in \mathbb{R}^{+}\right\}$is said to be uniformly asymptotically regular on $X$ if for all $h \geq 0$ and any bounded subset $C$ of $X$, $\lim _{t \rightarrow \infty} \sup _{x \in C}\|T(h) T(t) t x-T(t) x\|=0$ (see [5] for examples of uniformly asymptotically regular semigroups).

Recently, convergence theorems for common fixed points of a strongly continuous semigroup of nonexpansive mappings and their generalizations have been studied by numerous authors (see, e.g., [6-10]). Construction of fixed points of nonexpansive mappings (and of common fixed points of nonexpansive semigroups) is an important subject in the theory of nonexpansive mappings and finds application in a number of applied areas, in particular, in image recovery and signal processing (see, e.g., [11-16]). In the last ten years, the iterative methods for nonexpansive mappings have been applied to solve convex minimization problems; see, e.g., [17-19]. Let $H$ be a real Hilbert space, whose inner product and norm are denoted by $\langle\cdot, \cdot\rangle$ and $\|\cdot\|$, respectively. Let $A$ be a strongly positive bounded linear operator on $H$; that is, there is a constant $\bar{\gamma}>0$ with the property

$$
\langle A x, x\rangle \geq \bar{\gamma}\|x\|^{2} \quad \text { for all } x \in H .
$$

A typical problem is to minimize a quadratic function over the set of the fixed points of a nonexpansive mapping on a real Hilbert space $H$ :

$$
\min _{x \in F} \frac{1}{2}\langle A x, x\rangle-\langle x, b\rangle
$$

where $C$ is the fixed point set of a nonexpansive mapping $T$ on $H$ and $b$ is a given point in $H$.

In 2003, Xu [19] proved that the sequence $\left\{x_{n}\right\}$ defined by the iterative method below, with the initial guess $x_{0} \in H$ chosen arbitrarily,

$$
x_{n+1}=\left(I-\alpha_{n} A\right) T x_{n}+\alpha_{n} u, \quad \forall n \geq 0,
$$

converges strongly to the unique solution of the minimization problem (1.2) provided the sequence $\left\{\alpha_{n}\right\}$ satisfies certain conditions. Using the viscosity approximation method, 
Moudafi [20] introduced the following iterative process for nonexpansive mappings (see [19] for further developments in both Hilbert and Banach spaces). Let $f$ be a contraction on $H$. Starting with an arbitrary initial $x_{0} \in H$, we define the sequence $\left\{x_{n}\right\}$ recursively by

$$
x_{n+1}=\sigma_{n} f\left(x_{n}\right)+\left(1-\sigma_{n}\right) T x_{n}, \quad \forall n \geq 0,
$$

where $\left\{\sigma_{n}\right\}$ is a sequence in $(0,1)$. It is proved in $[19,20]$ that under certain appropriate conditions imposed on $\left\{\sigma_{n}\right\}$, the sequence $\left\{x_{n}\right\}$ generated by (1.4) strongly converges to a unique solution $x^{*}$ of the variational inequality

$$
\left\langle(f-I) x^{*}, x-x^{*}\right\rangle \leq 0, \quad \forall x \in F(T) .
$$

In 2006, Marino and Xu [21] combined the iterative method (1.3) with the viscosity approximation method (1.4) considering the following general iterative process:

$$
x_{n+1}=\alpha_{n} \gamma f\left(x_{n}\right)+\left(I-\alpha_{n} A\right) T x_{n}, \quad \forall n \geq 0,
$$

where $0<\gamma<\frac{\bar{\gamma}}{\alpha}$. They proved that the sequence $\left\{x_{n}\right\}$ generated by (1.6) converges strongly to a unique solution $x^{*}$ of the variational inequality

$$
\left\langle(\gamma f-A) x^{*}, x-x^{\prime \prime}\right\rangle \leq 0, \quad \forall x \in F(T),
$$

which is the optimality condition for the minimization problem

$$
\min _{x \in C} \frac{1}{2}\langle A x, x\rangle-h(x)
$$

where $h$ is a potential function for $\gamma f$ (i.e., $h^{\prime}(x)=\gamma f(x)$ for $x \in H$ ).

On the other hand, Li et al. [22] considered the implicit and explicit viscosity iteration processes for a nonexpansive semigroup $\mathcal{S}=\left\{T(t): t \in \mathbb{R}^{+}\right\}$in a Hilbert space as follows:

$$
\begin{array}{ll}
x_{n}=\alpha_{n} \gamma f\left(x_{n}\right)+\left(I-\alpha_{n} A\right) \frac{1}{t_{n}} \int_{0}^{t_{n}} T(s) x_{n} d s, & \forall n \in \mathbb{N}, \\
x_{n+1}=\alpha_{n} \gamma f\left(x_{n}\right)+\left(I-\alpha_{n} A\right) \frac{1}{t_{n}} \int_{0}^{t_{n}} T(s) x_{n} d s, & \forall n \in \mathbb{N},
\end{array}
$$

where $\left\{\alpha_{n}\right\}$ and $\left\{t_{n}\right\}$ are two sequences satisfying certain conditions. They proved the sequence $\left\{x_{n}\right\}$ defined by (1.8) and (1.9) converges strongly to $x^{*} \in \operatorname{Fix}(\mathcal{S})$, which solves the variational inequality (1.7). Under the framework of a uniformly convex Banach space with a uniformly Gâteaux differentiable norm, Chen and Song [23] studied the strong convergence of the implicit and explicit viscosity iteration processes for a nonexpansive semigroup $\mathcal{S}=\left\{T(t): t \in \mathbb{R}^{+}\right\}$with $\operatorname{Fix}(\mathcal{S}) \neq \emptyset$ as follows:

$$
\begin{aligned}
& x_{n}=\alpha_{n} f\left(x_{n}\right)+\left(1-\alpha_{n}\right) \frac{1}{t_{n}} \int_{0}^{t_{n}} T(s) x_{n} d s, \quad \forall n \in \mathbb{N}, \\
& x_{n+1}=\alpha_{n} f\left(x_{n}\right)+\left(1-\alpha_{n}\right) \frac{1}{t_{n}} \int_{0}^{t_{n}} T(s) x_{n} d s, \quad \forall n \in \mathbb{N} .
\end{aligned}
$$


Very recently, Zegeye et al. [7] introduced the implicit and explicit iterative processes for a strongly continuous semigroup of asymptotically nonexpansive mappings $\mathcal{S}=\{T(t): t \in$ $\left.\mathbb{R}^{+}\right\}$in a reflexive and strictly convex Banach spaces with a uniformly Gâteaux differentiable norm as follows:

$$
\begin{aligned}
& x_{n}=\alpha_{n} u+\left(1-\alpha_{n}\right) \frac{1}{t_{n}} \int_{0}^{t_{n}} T(s) x_{n} d s, \quad \forall n \in \mathbb{N}, \\
& x_{n+1}=\alpha_{n} u+\left(1-\alpha_{n}\right) \frac{1}{t_{n}} \int_{0}^{t_{n}} T(s) x_{n} d s, \quad \forall n \in \mathbb{N} .
\end{aligned}
$$

They proved that $\left\{x_{n}\right\}$ defined by (1.12) and (1.13) converges strongly to a common fixed point of $\operatorname{Fix}(\mathcal{S})$ provided certain conditions are satisfied.

In this paper, motivated by the above results, we introduce two iterative algorithms for finding a common fixed point of a semigroup of asymptotically nonexpansive mappings which is a unique solution of some variational inequality. We establish the strong convergence results in a uniformly convex Banach space which admits a weakly continuous duality mapping. The results in this article improve and extend the recent ones announced by Li et al. [22], Zegeye et al. [7] and many others.

\section{Preliminaries}

Throughout this paper, we write $x_{n} \rightarrow x$ (respectively $\left.x_{n} \rightarrow^{*} x\right)$ to indicate that the sequence $\left\{x_{n}\right\}$ weakly (respectively weak") converges to $x$; as usual $x_{n} \longrightarrow x$ will symbolize strong convergence; also, a mapping $I$ will denote the identity mapping. Let $X$ be a real Banach space, $X^{*}$ be its dual space. Let $U=\{x \in X:\|x\|=1\}$. A Banach space $X$ is said to be uniformly convex if, for each $\epsilon \in(0,2]$, there exists a $\delta>0$ such that for each $x, y \in U$, $\|x-y\| \geq \epsilon$ implies $\frac{\|x+y\|}{2} \leq 1-\delta$. It is know that a uniformly convex Banach space is reflexive and strictly convex (see also [24]). A Banach space is said to be smooth if the limit $\lim _{t \rightarrow 0} \frac{\|x+t y\|-\|x\|}{t}$ exists for each $x, y \in U$. It is also said to be uniformly smooth if the limit is attained uniformly for $x, y \in U$.

Let $\varphi:[0, \infty) \longrightarrow[0, \infty)$ be a continuous strictly increasing function such that $\varphi(0)=0$ and $\varphi(t) \longrightarrow \infty$ as $t \longrightarrow \infty$. This function $\varphi$ is called a gauge function. The duality mapping $J_{\varphi}: X \longrightarrow 2^{X^{*}}$ associated with a gauge function $\varphi$ is defined by

$$
J_{\varphi}(x)=\left\{f^{*} \in X^{*}:\left\langle x, f^{*}\right\rangle=\|x\| \varphi(\|x\|),\left\|f^{*}\right\|=\varphi(\|x\|), \forall x \in X\right\}
$$

where $\langle\cdot, \cdot\rangle$ denotes the generalized duality paring. In particular, the duality mapping with the gauge function $\varphi(t)=t$, denoted by $J$ is referred to as the normalized duality mapping. Clearly, the relation $J_{\varphi}(x)=\frac{\varphi(\|x\|)}{\|x\|} J(x)$ holds for each $x \neq 0$ (see [25]).

Browder [25] initiated the study of certain classes of nonlinear operators by means of the duality mapping $J_{\varphi}$. Following Browder [25], we say a Banach space $X$ has a weakly continuous duality mapping if there exits a gauge function $\varphi$ for which the duality mapping $J_{\varphi}(x)$ is single-valued and continuous from the weak topology to the weak" topology; that is, for each $\left\{x_{n}\right\}$ with $x_{n} \rightarrow x$, the sequence $\left\{J\left(x_{n}\right)\right\}$ converges weakly" to $J_{\varphi}(x)$. It is known that $l^{p}$ has a weakly continuous duality mapping with a gauge function $\varphi(t)=t^{p-1}$ for all $1<p<\infty$. Set $\Phi(t)=\int_{0}^{t} \varphi(\tau) d \tau, \forall t \geq 0$, then $J_{\varphi}(x)=\partial \Phi(\|x\|)$, where $\partial$ denotes the subdifferential in the sense of convex analysis (recall that the subdifferential of the convex function $\phi: X \longrightarrow \mathbb{R}$ at $x \in X$ is the set $\left.\partial \phi(x)=\left\{x^{*} \in X ; \phi(y) \geq \phi(x)+\left\langle x^{*}, y-x\right\rangle, \forall y \in X\right\}\right)$. 
In a Banach space $X$ which admits a duality mapping $J_{\varphi}$ with a gauge function $\varphi$, we say that an operator $A$ is strongly positive (see [26]) if there exists a constant $\bar{\gamma}>0$ with the property

$$
\left\langle A x, J_{\varphi}(x)\right\rangle \geq \bar{\gamma}\|x\| \varphi(\|x\|)
$$

and

$$
\|a I-b A\|=\sup _{\|x\| \leq 1}\left|\left\langle(a I-b A) x, J_{\varphi}(x)\right\rangle\right|, \quad a \in[0,1], b \in[-1,1] .
$$

As special cases of (2.1), we have the following results.

(1) If $X$ is a smooth Banach space and $\varphi(t)=t$ for all $t \in X$ (see [27]), then the inequality (2.1) reduces to

$$
\langle A x, J(x)\rangle \geq \bar{\gamma}\|x\|^{2} .
$$

(2) If $X:=H$ is a real Hilbert space, then the inequality (2.1) reduces to (1.1).

The first part of the next lemma is an immediate consequence of the subdifferential inequality and the proof of the second part can be found in [28].

Lemma 2.1 ([28]) Assume that a Banach space X has a weakly continuous duality mapping $J_{\varphi}$ with a gauge $\varphi$.

(i) For all $x, y \in X$, the following inequality holds:

$$
\Phi(\|x+y\|) \leq \Phi(\|x\|)+\left\langle y, J_{\varphi}(x+y)\right\rangle .
$$

(ii) Assume that a sequence $\left\{x_{n}\right\}$ in $X$ converges weakly to a point $x \in X$. Then the following identity holds:

$$
\limsup _{n \rightarrow \infty} \Phi\left(\left\|x_{n}-y\right\|\right)=\limsup _{n \rightarrow \infty} \Phi\left(\left\|x_{n}-x\right\|\right)+\Phi(\|y-x\|), \quad \forall x, y \in X .
$$

Lemma 2.2 ([26]) Assume that a Banach space $X$ admits a duality mapping $J_{\varphi}$ with a gauge $\varphi$. Let $A$ be a strongly positive linear bounded operator on $X$ with a coefficient $\bar{\gamma}>0$ and $0<\rho \leq \varphi(1)\|A\|^{-1}$. Then $\|I-\rho A\| \leq \varphi(1)(1-\rho \bar{\gamma})$.

Definition 2.3 Let $C$ be a closed convex subset of a real Banach space $X$. Let $\mathcal{S}=\{T(t): t \in$ $\mathbb{R}^{+}$\} be a strongly continuous semigroup of asymptotically nonexpansive mappings from $C$ into itself such that $\operatorname{Fix}(\mathcal{S}) \neq \emptyset$. Then $\mathcal{S}$ is said to be almost uniformly asymptotically regular (in short a.u.a.r.) on $C$, if for all $h \geq 0$,

$$
\lim _{t \rightarrow \infty} \sup _{x \in C}\left\|\frac{1}{t} \int_{0}^{t} T(s) x d s-T(h)\left(\frac{1}{t} \int_{0}^{t} T(s) x d s\right)\right\|=0
$$

Lemma 2.4 ([7]) Let $C$ be a closed convex subset of a uniformly convex Banach space $X$ and $\mathcal{S}=\left\{T(t): t \in \mathbb{R}^{+}\right\}$be a strongly continuous semigroup of asymptotically nonexpansive 
mappings from $C$ into itself with a sequence $\left\{L_{t}\right\} \subset[1, \infty)$ such that $\operatorname{Fix}(\mathcal{S}) \neq \emptyset$. Then for each $r>0$ and $h \geq 0$,

$$
\lim _{t \rightarrow \infty} \sup _{x \in C \cap B_{r}}\left\|\frac{1}{t} \int_{0}^{t} T(s) x d s-T(h)\left(\frac{1}{t} \int_{0}^{t} T(s) x d s\right)\right\|=0 .
$$

Lemma 2.5 ([29]) Assume that $\left\{a_{n}\right\}$ is a sequence of nonnegative real numbers such that

$$
a_{n+1} \leq\left(1-\sigma_{n}\right) a_{n}+\delta_{n}
$$

where $\left\{\sigma_{n}\right\}$ is a sequence in $(0,1)$ and $\left\{\delta_{n}\right\}$ is a sequence in $\mathbb{R}$ such that

(i) $\sum_{n=0}^{\infty} \sigma_{n}=\infty$;

(ii) $\lim \sup _{n \rightarrow \infty} \frac{\delta_{n}}{\sigma_{n}} \leq 0$ or $\sum_{n=0}^{\infty}\left|\delta_{n}\right|<\infty$.

Then $\lim _{n \rightarrow \infty} a_{n}=0$.

\section{Implicit iteration scheme}

Theorem 3.1 Let $X$ be a uniformly convex Banach space which admits a weakly continuous duality mapping $J_{\varphi}$ with a gauge $\varphi$ such that $\varphi$ is invariant on $[0,1]$. Let $\mathcal{S}=\{T(t)$ : $t \in \mathbb{R}^{+}$be a strongly continuous semigroup of asymptotically nonexpansive mappings from $X$ into itself with a sequence $\left\{L_{t}\right\} \subset[1, \infty)$ such that $\operatorname{Fix}(\mathcal{S}) \neq \emptyset$. Let $f: X \rightarrow X$ be a contraction mapping with a constant $\alpha \in(0,1)$ and $A: X \longrightarrow X$ be a strongly positive linear bounded operator with a constant $\bar{\gamma} \in(0,1)$ such that $0<\gamma<\frac{\bar{\gamma} \varphi(1)}{\alpha}$. Let $\left\{x_{n}\right\}$ be a sequence defined by

$$
x_{n}=\alpha_{n} \gamma f\left(x_{n}\right)+\left(I-\alpha_{n} A\right) \frac{1}{t_{n}} \int_{0}^{t_{n}} T(s) x_{n} d s, \quad \forall n \geq 1,
$$

where $\left\{\alpha_{n}\right\}$ is a sequence in $(0,1)$ and $\left\{t_{n}\right\}$ is a positive real divergent sequence which satisfy the following conditions:

(C1) $\lim _{n \rightarrow \infty} \alpha_{n}=0$;

(C2) $\lim _{n \rightarrow \infty} \frac{\left(\frac{1}{t_{n}} \int_{0}^{t_{n}} L_{s} d s\right)-1}{\alpha_{n}}=0$.

Then the sequence $\left\{x_{n}\right\}$ defined by (3.1) converges strongly to $x^{*} \in \operatorname{Fix}(\mathcal{S})$, where $x^{*}$ is the unique solution of the variational inequality

$$
\left\langle\gamma f\left(x^{\prime \prime}\right)-A x^{\prime \prime}, J_{\varphi}\left(v-x^{\prime \prime}\right)\right\rangle \leq 0, \quad \forall v \in \operatorname{Fix}(\mathcal{S}) .
$$

Proof First, we show that $\left\{x_{n}\right\}$ defined by (3.1) is well defined. For all $n \in \mathbb{N}$, let us define the mapping

$$
T_{n}^{f}:=\alpha_{n} \gamma f+\left(I-\alpha_{n} A\right) \frac{1}{t_{n}} \int_{0}^{t_{n}} T(s) d s .
$$

Indeed, for all $x, y \in X$, we have

$$
\begin{aligned}
\left\|T_{n}^{f} x-T_{n}^{f} y\right\| & =\left\|\alpha_{n} \gamma(f(x)-f(y))+\left(I-\alpha_{n} A\right)\left(\frac{1}{t_{n}} \int_{0}^{t_{n}}(T(s) x-T(s) y) d s\right)\right\| \\
& \leq \alpha_{n} \gamma\|f(x)-f(y)\|+\left\|I-\alpha_{n} A\right\|\left(\frac{1}{t_{n}} \int_{0}^{t_{n}}\|T(s) x-T(s) y\| d s\right)
\end{aligned}
$$




$$
\begin{aligned}
& \leq \alpha_{n} \gamma \alpha\|x-y\|+\varphi(1)\left(1-\alpha_{n} \bar{\gamma}\right)\left(\frac{1}{t_{n}} \int_{0}^{t_{n}} L_{s} d s\right)\|x-y\| \\
& \leq\left[\frac{1}{t_{n}} \int_{0}^{t_{n}} L_{s} d s-\varphi(1) \bar{\gamma}\left(\frac{1}{t_{n}} \int_{0}^{t_{n}} L_{s} d s\right) \alpha_{n}+\gamma \alpha \alpha_{n}\right]\|x-y\| .
\end{aligned}
$$

Since $\lim _{n \rightarrow \infty} \frac{\left(\frac{1}{t_{n}} \int_{0}^{t_{n}} L_{s} d s\right)-1}{\alpha_{n}}=0$ implies

$$
\frac{\left(\frac{1}{t_{n}} \int_{0}^{t_{n}} L_{s} d s\right)-1}{\alpha_{n}}<\varphi(1) \bar{\gamma}-\gamma \alpha \leq \varphi(1) \bar{\gamma}\left(\frac{1}{t_{n}} \int_{0}^{t_{n}} L_{s} d s\right)-\gamma \alpha,
$$

for sufficiently large $n \geq 1$, that is,

$$
\frac{1}{t_{n}} \int_{0}^{t_{n}} L_{s} d s-\varphi(1) \bar{\gamma}\left(\frac{1}{t_{n}} \int_{0}^{t_{n}} L_{s} d s\right) \alpha_{n}+\gamma \alpha \alpha_{n}<1 .
$$

Thus, by the Banach contraction mapping principle, there exits a unique fixed point $x_{n} \in$ $X$, that is, $\left\{x_{n}\right\}$ defined by (3.1) is well defined.

Next, we show the uniqueness of a solution of the variational inequality (3.2). Suppose that $\tilde{x}, x^{*} \in F(\mathcal{S})$ are solutions of (3.2), then

$$
\left\langle\gamma f\left(x^{*}\right)-A x^{*}, J_{\varphi}\left(\tilde{x}-x^{*}\right)\right\rangle \leq 0
$$

and

$$
\left\langle\gamma f(\tilde{x})-A \tilde{x}, J_{\varphi}\left(x^{*}-\tilde{x}\right)\right\rangle \leq 0
$$

Adding up (3.3) and (3.4), we obtain

$$
\begin{aligned}
0 & \geq\left\langle\left(\gamma f\left(x^{*}\right)-A x^{*}\right)-(\gamma f(\tilde{x})-A \tilde{x}), J_{\varphi}\left(\tilde{x}-x^{*}\right)\right\rangle \\
& =\left\langle A\left(\tilde{x}-x^{*}\right), J_{\varphi}\left(\tilde{x}-x^{*}\right)\right\rangle-\gamma\left\langle f(\tilde{x})-f\left(x^{*}\right), J_{\varphi}\left(\tilde{x}-x^{*}\right)\right\rangle \\
& \geq \bar{\gamma}\left\|\tilde{x}-x^{*}\right\| \varphi\left(\left\|\tilde{x}-x^{*}\right\|\right)-\gamma\left\|f(\tilde{x})-f\left(x^{*}\right)\right\|\left\|J_{\varphi}\left(\tilde{x}-x^{*}\right)\right\| \\
& \geq \bar{\gamma} \Phi\left(\left\|\tilde{x}-x^{*}\right\|\right)-\gamma \alpha \Phi\left(\left\|\tilde{x}-x^{*}\right\|\right) \\
& =(\bar{\gamma}-\gamma \alpha) \Phi\left(\left\|\tilde{x}-x^{*}\right\|\right) \\
& \geq(\varphi(1) \bar{\gamma}-\gamma \alpha) \Phi\left(\left\|\tilde{x}-x^{*}\right\|\right),
\end{aligned}
$$

which is a contradiction. We must have $\tilde{x}=x^{*}$ and the uniqueness is proved. Below, we use $\tilde{x}$ to denote the unique solution of the variational inequality (3.2).

Next, we show that $\left\{x_{n}\right\}$ is bounded. Take $p \in \operatorname{Fix}(\mathcal{S})$. Then from (3.1), we get that

$$
\begin{aligned}
\left\|x_{n}-p\right\|= & \left\|\alpha_{n}\left(\gamma f\left(x_{n}\right)-A p\right)+\left(I-\alpha_{n} A\right)\left(\frac{1}{t_{n}} \int_{0}^{t_{n}} T(s) x_{n} d s-p\right)\right\| \\
\leq & \alpha_{n}\left\|\gamma f\left(x_{n}\right)-A p\right\|+\varphi(1)\left(1-\alpha_{n} \bar{\gamma}\right)\left\|\frac{1}{t_{n}} \int_{0}^{t_{n}} T(s) x_{n} d s-p\right\| \\
\leq & \alpha_{n} \gamma\left\|f\left(x_{n}\right)-f(p)\right\|+\alpha_{n}\|\gamma f(p)-A p\| \\
& +\varphi(1)\left(1-\alpha_{n} \bar{\gamma}\right)\left(\frac{1}{t_{n}} \int_{0}^{t_{n}} L_{s} d s\right)\left\|x_{n}-p\right\|
\end{aligned}
$$




$$
\begin{aligned}
\leq & {\left[\frac{1}{t_{n}} \int_{0}^{t_{n}} L_{s} d s-\left(\varphi(1) \bar{\gamma}\left(\frac{1}{t_{n}} \int_{0}^{t_{n}} L_{s} d s\right)-\gamma \alpha\right) \alpha_{n}\right]\left\|x_{n}-p\right\| } \\
& +\alpha_{n}\|\gamma f(p)-A p\| .
\end{aligned}
$$

It follows that

$$
\left\|x_{n}-p\right\| \leq \frac{1}{\varphi(1) \bar{\gamma}\left(\frac{1}{t_{n}} \int_{0}^{t_{n}} L_{s} d s\right)-\gamma \alpha-d_{n}}\|\gamma f(p)-A p\|,
$$

where $d_{n}=\frac{\left(\frac{1}{t_{n}} \int_{0}^{t_{n}} L_{s} d s\right)-1}{\alpha_{n}}$. Thus, there exists $n \geq 1$ such that

$$
\left\|x_{n}-p\right\| \leq \frac{1}{\varphi(1) \bar{\gamma}-\gamma \alpha}\|\gamma f(p)-A p\| .
$$

Hence, $\left\{x_{n}\right\}$ is bounded, so are $\left\{f\left(x_{n}\right)\right\}$ and $\left\{A\left(\frac{1}{t_{n}} \int_{0}^{t_{n}} T(s) x_{n} d s\right)\right\}$.

Next, we show that $\left\|x_{n}-T(h) x_{n}\right\| \longrightarrow 0$ as $n \longrightarrow \infty$. From (3.1), we note that

$$
\left\|x_{n}-\frac{1}{t_{n}} \int_{0}^{t_{n}} T(s) x_{n} d s\right\|=\alpha_{n}\left\|\gamma f\left(x_{n}\right)-A\left(\frac{1}{t_{n}} \int_{0}^{t_{n}} T(s) x_{n} d s\right)\right\| .
$$

By the condition (C1), we obtain

$$
\lim _{n \rightarrow \infty}\left\|x_{n}-\frac{1}{t_{n}} \int_{0}^{t_{n}} T(s) x_{n} d s\right\|=0 .
$$

For all $h \geq 0$, we note that

$$
\begin{aligned}
\left\|x_{n}-T(h) x_{n}\right\| \leq & \left\|x_{n}-\frac{1}{t_{n}} \int_{0}^{t_{n}} T(s) x_{n} d s\right\| \\
& +\left\|\frac{1}{t_{n}} \int_{0}^{t_{n}} T(s) x_{n} d s-T(h)\left(\frac{1}{t_{n}} \int_{0}^{t_{n}} T(s) x_{n} d s\right)\right\| \\
& +\left\|T(h)\left(\frac{1}{t_{n}} \int_{0}^{t_{n}} T(s) x_{n} d s\right)-T(h) x_{n}\right\| \\
\leq & \left\|x_{n}-\frac{1}{t_{n}} \int_{0}^{t_{n}} T(s) x_{n} d s\right\| \\
& +\left\|\frac{1}{t_{n}} \int_{0}^{t_{n}} T(s) x_{n} d s-T(h)\left(\frac{1}{t_{n}} \int_{0}^{t_{n}} T(s) x_{n} d s\right)\right\| \\
& +L_{h}\left\|x_{n}-\frac{1}{t_{n}} \int_{0}^{t_{n}} T(s) x_{n} d s\right\| .
\end{aligned}
$$

By Lemma 2.4 and (3.5), we obtain

$$
\lim _{n \rightarrow \infty}\left\|x_{n}-T(h) x_{n}\right\|=0 \quad \text { for all } h \geq 0 .
$$

Next, we show that $\tilde{x} \in \operatorname{Fix}(\mathcal{S})$. By reflexivity of $X$ and boundedness of $\left\{x_{n}\right\}$, there exists a weakly convergent subsequence $\left\{x_{n_{j}}\right\}$ of $\left\{x_{n}\right\}$ such that $x_{n_{j}} \rightarrow \tilde{x} \in X$ as $j \longrightarrow \infty$. Since $J_{\varphi}$ is 
weakly continuous, we have by Lemma 2.1 that

$$
\limsup _{j \rightarrow \infty} \Phi\left(\left\|x_{n_{j}}-x\right\|\right)=\limsup _{j \rightarrow \infty} \Phi\left(\left\|x_{n_{j}}-\tilde{x}\right\|\right)+\Phi(\|x-\tilde{x}\|) \quad \text { for all } x \in X .
$$

Let $H(x)=\limsup _{j \rightarrow \infty} \Phi\left(\left\|x_{n_{j}}-x\right\|\right)$ for all $x \in X$. It follows that

$$
H(x)=H(\tilde{x})+\Phi(\|x-\tilde{x}\|) \quad \text { for all } x \in X .
$$

Since $\Phi$ is continuous and $\lim _{h \rightarrow \infty} L_{h}=1$, it follows from (3.6) that

$$
\begin{aligned}
H\left(\lim _{h \rightarrow \infty} T(h) \tilde{x}\right) & =\lim _{h \rightarrow \infty} H(T(h) \tilde{x}) \\
& =\lim _{h \rightarrow \infty} \limsup _{j \rightarrow \infty} \Phi\left(\left\|x_{n_{j}}-T(h) \tilde{x}\right\|\right) \\
& =\lim _{h \rightarrow \infty} \limsup _{j \rightarrow \infty} \Phi\left(\left\|T(h) x_{n_{j}}-T(h) \tilde{x}\right\|\right) \\
& \leq \lim _{h \rightarrow \infty} \limsup _{j \rightarrow \infty} \Phi\left(L_{h}\left\|x_{n_{j}}-\tilde{x}\right\|\right) \\
& =\limsup _{j \rightarrow \infty} \Phi\left(\left\|x_{n_{j}}-\tilde{x}\right\|\right) \\
& =H(\tilde{x}) .
\end{aligned}
$$

On the other hand, we note that

$$
\begin{aligned}
H\left(\lim _{h \rightarrow \infty} T(h) \tilde{x}\right) & =\lim _{h \rightarrow \infty} \limsup _{j \rightarrow \infty} \Phi\left(\left\|x_{n_{j}}-\tilde{x}\right\|\right)+\lim _{h \rightarrow \infty} \Phi(\|T(h) \tilde{x}-\tilde{x}\|) \\
& =\limsup _{j \rightarrow \infty} \Phi\left(\left\|x_{n_{j}}-\tilde{x}\right\|\right)+\Phi\left(\lim _{h \rightarrow \infty}\|T(h) \tilde{x}-\tilde{x}\|\right) .
\end{aligned}
$$

Combining (3.7) and (3.8), we obtain $\Phi\left(\lim _{h \rightarrow \infty}\|T(h) \tilde{x}-\tilde{x}\|\right) \leq 0$. The property of $\Phi$ implies that $\lim _{h \rightarrow \infty} T(h) \tilde{x}=\tilde{x}$. In fact, since $T(t+h) x=T(t) T(h) x$ for all $x \in X$ and $t \geq 0$, then we have

$$
\begin{aligned}
\tilde{x} & =\lim _{h \rightarrow \infty} T(h) \tilde{x}=\lim _{h \rightarrow \infty} T(h+t) \tilde{x}=\lim _{h \rightarrow \infty} T(h) T(t) \tilde{x} \\
& =T(t) \lim _{h \rightarrow \infty} T(h) \tilde{x}=T(t) \tilde{x},
\end{aligned}
$$

for all $t \geq 0$. Hence, $\tilde{x} \in \operatorname{Fix}(\mathcal{S})$.

Next, we show that $\left\{x_{n}\right\}$ is sequentially compact. Since $\Phi(t)=\int_{0}^{t} \varphi(\tau) d \tau, \forall t \geq 0$ and $\varphi:[0, \infty) \longrightarrow[0, \infty)$ is the gauge function, then for $1 \geq k \geq 0, \varphi(k y) \leq \varphi(y)$ and

$$
\Phi(k t)=\int_{0}^{k t} \varphi(\tau) d \tau=k \int_{0}^{t} \varphi(k y) d y \leq k \int_{0}^{t} \varphi(y) d y=k \Phi(t) .
$$


By Lemma 2.1, we have

$$
\begin{aligned}
\Phi\left(\left\|x_{n}-\tilde{x}\right\|\right)= & \Phi\left(\left\|\alpha_{n}\left(\gamma f\left(x_{n}\right)-A \tilde{x}\right)+\left(I-\alpha_{n} A\right)\left(\frac{1}{t_{n}} \int_{0}^{t_{n}} T(s) x_{n} d s-\tilde{x}\right)\right\|\right) \\
\leq & \Phi\left(\left\|\left(I-\alpha_{n} A\right)\left(\frac{1}{t_{n}} \int_{0}^{t_{n}} T(s) x_{n} d s-\tilde{x}\right)\right\|\right)+\alpha_{n}\left\langle\gamma f\left(x_{n}\right)-A \tilde{x}, J_{\varphi}\left(x_{n}-\tilde{x}\right)\right\rangle \\
= & \Phi\left(\left\|\left(I-\alpha_{n} A\right)\left(\frac{1}{t_{n}} \int_{0}^{t_{n}} T(s) x_{n} d s-\tilde{x}\right)\right\|\right)+\alpha_{n} \gamma\left\langle f\left(x_{n}\right)-f(\tilde{x}), J_{\varphi}\left(x_{n}-\tilde{x}\right)\right\rangle \\
& +\alpha_{n}\left\langle\gamma f(\tilde{x})-A \tilde{x}, J_{\varphi}\left(x_{n}-\tilde{x}\right)\right\rangle \\
\leq & {\left[\frac{1}{t_{n}} \int_{0}^{t_{n}} L_{s} d s-(\varphi(1) \bar{\gamma}-\gamma \alpha) \alpha_{n}\right] \Phi\left(\left\|x_{n}-\tilde{x}\right\|\right) } \\
& +\alpha_{n}\left\langle\gamma f(\tilde{x})-A \tilde{x}, J_{\varphi}\left(x_{n}-\tilde{x}\right)\right\rangle,
\end{aligned}
$$

which implies that

$$
\Phi\left(\left\|x_{n}-\tilde{x}\right\|\right) \leq \frac{1}{\varphi(1) \bar{\gamma}-\gamma \alpha-d_{n}}\left\langle\gamma f(\tilde{x})-A \tilde{x}, J_{\varphi}\left(x_{n}-\tilde{x}\right)\right\rangle,
$$

where $d_{n}=\frac{\left(\frac{1}{t_{n}} \int_{0}^{t_{n}} L_{s} d s\right)-1}{\alpha_{n}}$. Thus, there exists $n \geq 1$ such that

$$
\Phi\left(\left\|x_{n}-\tilde{x}\right\|\right) \leq \frac{1}{\varphi(1) \bar{\gamma}-\gamma \alpha}\left\langle\gamma f(\tilde{x})-A \tilde{x}, J_{\varphi}\left(x_{n}-\tilde{x}\right)\right\rangle .
$$

In particular, we have

$$
\Phi\left(\left\|x_{n_{j}}-\tilde{x}\right\|\right) \leq \frac{1}{\varphi(1) \bar{\gamma}-\gamma \alpha}\left\langle\gamma f(\tilde{x})-A \tilde{x}, J_{\varphi}\left(x_{n_{j}}-\tilde{x}\right)\right\rangle .
$$

Since $J_{\varphi}$ is single-valued and weakly continuous, it follows that $\Phi\left(\left\|x_{n_{j}}-\tilde{x}\right\|\right) \longrightarrow 0$ as $j \longrightarrow$ $\infty$. The property of $\Phi$ implies that $x_{n_{j}} \longrightarrow \tilde{x}$ as $j \rightarrow \infty$.

Next, we show that $\tilde{x}$ solves the variational inequality (3.2). From (3.1), we derive that

$$
A\left(\frac{1}{t_{n}} \int_{0}^{t_{n}} T(s) x_{n} d s\right)-\gamma f\left(x_{n}\right)=\frac{1}{\alpha_{n}}\left(\frac{1}{t_{n}} \int_{0}^{t_{n}} T(s) x_{n} d s-x_{n}\right) .
$$

For all $v \in \operatorname{Fix}(\mathcal{S})$, it follows from $(3.10)$ that

$$
\begin{aligned}
\langle A & \left.\left(\frac{1}{t_{n}} \int_{0}^{t_{n}} T(s) x_{n} d s\right)-\gamma f\left(x_{n}\right), J_{\varphi}\left(x_{n}-v\right)\right\rangle \\
\quad & =\frac{1}{\alpha_{n}}\left\langle\frac{1}{t_{n}} \int_{0}^{t_{n}} T(s) x_{n} d s-x_{n}, J_{\varphi}\left(x_{n}-v\right)\right\rangle \\
& =\frac{1}{\alpha_{n}}\left[\left\langle\frac{1}{t_{n}} \int_{0}^{t_{n}} T(s) x_{n} d s-v, J_{\varphi}\left(x_{n}-v\right)\right\rangle-\left\langle x_{n}-v, J_{\varphi}\left(x_{n}-v\right)\right\rangle\right] \\
& \leq \frac{1}{\alpha_{n}}\left[\left(\frac{1}{t_{n}} \int_{0}^{t_{n}} L_{s} d s\right) \Phi\left(\left\|x_{n}-v\right\|\right)-\Phi\left(\left\|x_{n}-v\right\|\right)\right] \\
& =\frac{\left(\frac{1}{t_{n}} \int_{0}^{t_{n}} L_{s} d s\right)-1}{\alpha_{n}} \Phi\left(\left\|x_{n}-v\right\|\right) .
\end{aligned}
$$


Now, replacing $n$ by $n_{j}$ in (3.11) and letting $j \longrightarrow \infty$, we notice that

$$
x_{n_{j}}-\frac{1}{t_{n_{j}}} \int_{0}^{t_{n_{j}}} T(s) x_{n_{j}} d s \rightarrow 0 .
$$

By the condition (C2), we obtain that

$$
\left\langle\gamma f(\tilde{x})-A \tilde{x}, J_{\varphi}(\nu-\tilde{x})\right\rangle \leq 0, \quad \forall v \in \operatorname{Fix}(\mathcal{S}) .
$$

That is, $\tilde{x}$ is a solution of the variational inequality (3.2).

Finally, we show that $\left\{x_{n}\right\}$ converges strongly to $\tilde{x} \in \operatorname{Fix}(\mathcal{S})$. Suppose that there exists another subsequence $x_{n_{i}} \longrightarrow \hat{x}$ as $j \longrightarrow \infty$. We note that $\hat{x} \in \operatorname{Fix}(\mathcal{S})$ is the solution of the variational inequality (3.2). Hence, $\tilde{x}=\hat{x}=x^{*}$ by uniqueness. In summary, we have shown that $\left\{x_{n}\right\}$ is sequentially compact and each cluster point of the sequence $\left\{x_{n}\right\}$ is equal to $x^{*}$. Therefore, we conclude that $x_{n} \longrightarrow x^{*}$ as $n \rightarrow \infty$. This proof is complete.

Remark 3.2 Theorem 3.1 extends and generalizes Theorem 3.5 of Zegeye et al. [7], Theorem 3.1 of Chen and Song [23] and Theorem 3.1 of [22], in the following respects:

(1) Theorem 3.1 generalizes Theorem 3.5 of Zegeye et al. [7] to the viscosity iterative method in a different Banach space which admits a weakly continuous duality mapping.

(2) Theorem 3.1 improves Theorem 3.5 of Zegeye et al. [7] in the sense that our theorem is applicable in a uniformly convex Banach space without the requirement that $\mathcal{S}=\{T(t)$ : $\left.t \in \mathbb{R}^{+}\right\}$is almost uniformly asymptotically regular.

(3) Theorem 3.1 extends Theorem 3.1 of Chen and Song [23] from a class of strongly continuous semigroups of nonexpansive mappings to a more general class of strongly continuous semigroups of asymptotically nonexpansive mappings.

(4) Theorem 3.1 includes Theorem 3.1 of Li et al. [22] as a special case.

If $\mathcal{S}=\left\{T(t): t \in \mathbb{R}^{+}\right\}$is a strongly continuous semigroup of nonexpansive mappings, we have $L_{t} \equiv 1$ and then Theorem 3.1 is reduced to the following results.

Corollary 3.3 Let $X$ be a uniformly convex Banach space which admits a weakly continuous duality mapping $J_{\varphi}$ with a gauge $\varphi$ such that $\varphi$ is invariant on $[0,1]$. Let $\mathcal{S}=\{T(t): t \in$ $\mathbb{R}^{+}$be a strongly continuous semigroup of nonexpansive mappings from $X$ into itself such that $\operatorname{Fix}(\mathcal{S}) \neq \emptyset$. Let $f: X \longrightarrow X$ be a contraction mapping with a constant $\alpha \in(0,1)$ and $A: X \rightarrow X$ be a strongly positive linear bounded operator with a constant $\bar{\gamma} \in(0,1)$ such that $0<\gamma<\frac{\bar{\gamma} \varphi(1)}{\alpha}$. Let $\left\{x_{n}\right\}$ be a sequence defined by

$$
x_{n}=\alpha_{n} \gamma f\left(x_{n}\right)+\left(I-\alpha_{n} A\right) \frac{1}{t_{n}} \int_{0}^{t_{n}} T(s) x_{n} d s, \quad \forall n \geq 1,
$$

where $\left\{\alpha_{n}\right\}$ is a sequence in $(0,1)$ such that $\lim _{n \rightarrow \infty} \alpha_{n}=0$ and $\left\{t_{n}\right\}$ is a positive real divergent sequence. Then the sequence $\left\{x_{n}\right\}$ defined by (3.12) converges strongly to $x^{*} \in \operatorname{Fix}(\mathcal{S})$, where $x^{*}$ is the unique solution of the variational inequality

$$
\left\langle\gamma f\left(x^{\prime \prime}\right)-A x^{\prime \prime}, J_{\varphi}\left(v-x^{\prime \prime}\right)\right\rangle \leq 0, \quad \forall v \in \operatorname{Fix}(\mathcal{S}) .
$$


Corollary 3.4 ( $\mathrm{Li}$ et al. [22, Theorem 3.1]) Let $H$ be a real Hilbert space and $C$ be a nonempty closed convex subset of $X$ such that $C \pm C \subset C$. Let $\mathcal{S}=\left\{T(t): t \in \mathbb{R}^{+}\right\}$be a strongly continuous semigroup of nonexpansive mappings from $C$ into itself such that $\operatorname{Fix}(\mathcal{S}) \neq \emptyset$. Let $f: C \longrightarrow C$ be a contraction mapping with a constant $\alpha \in(0,1)$ and $A: C \longrightarrow C$ be a strongly positive linear bounded operator with a constant $\bar{\gamma} \in(0,1)$ such that $0<\gamma<\frac{\bar{\gamma}}{\alpha}$. Let $\left\{x_{n}\right\}$ be a sequence defined by

$$
x_{n}=\alpha_{n} \gamma f\left(x_{n}\right)+\left(I-\alpha_{n} A\right) \frac{1}{t_{n}} \int_{0}^{t_{n}} T(s) x_{n} d s, \quad \forall n \geq 1,
$$

where $\left\{\alpha_{n}\right\}$ is a sequence in $(0,1)$ such that $\lim _{n \rightarrow \infty} \alpha_{n}=0$ and $\left\{t_{n}\right\}$ is a positive real divergent sequence. Then the sequence $\left\{x_{n}\right\}$ defined by (3.14) converges strongly to $x^{*} \in \operatorname{Fix}(\mathcal{S})$, where $x^{*}$ is the unique solution of the variational inequality

$$
\left\langle\gamma f\left(x^{*}\right)-A x^{*}, v-x^{*}\right\rangle \leq 0, \quad \forall v \in \operatorname{Fix}(\mathcal{S}) .
$$

\section{Explicit iteration scheme}

Theorem 4.1 Let $X$ be a uniformly convex Banach space which admits a weakly continuous duality mapping $J_{\varphi}$ with a gauge $\varphi$ such that $\varphi$ is invariant on $[0,1]$. Let $\mathcal{S}=\{T(t)$ : $\left.t \in \mathbb{R}^{+}\right\}$be a strongly continuous semigroup of asymptotically nonexpansive mappings from $X$ into itself with a sequence $\left\{L_{t}\right\} \subset[1, \infty)$ such that $\operatorname{Fix}(\mathcal{S}) \neq \emptyset$. Let $f: X \rightarrow X$ be a contraction mapping with a constant $\alpha \in(0,1)$ and $A: X \rightarrow X$ be a strongly positive linear bounded operator with a constant $\bar{\gamma} \in(0,1)$ such that $0<\gamma<\frac{\bar{\gamma} \varphi(1)}{\alpha}$. For given $x_{1} \in X$, let $\left\{x_{n}\right\}$ be a sequence defined by

$$
x_{n+1}=\alpha_{n} \gamma f\left(x_{n}\right)+\left(I-\alpha_{n} A\right) \frac{1}{t_{n}} \int_{0}^{t_{n}} T(s) x_{n} d s, \quad \forall n \geq 1,
$$

where $\left\{\alpha_{n}\right\}$ is a sequence in $(0,1)$ and $\left\{t_{n}\right\}$ is a positive real divergent sequence which satisfy the following conditions:

(C1) $\lim _{n \rightarrow \infty} \alpha_{n}=0$ and $\sum_{n=1}^{\infty} \alpha_{n}=\infty$;

(C2) $\lim _{n \rightarrow \infty} \frac{\left(\frac{1}{t_{n}} \int_{0}^{t_{n}} L_{s} d s\right)-1}{\alpha_{n}}=0$.

Then the sequence $\left\{x_{n}\right\}$ defined by (4.1) converges strongly to $x^{*} \in \operatorname{Fix}(\mathcal{S})$, where $x^{*}$ is the unique solution of the variational inequality

$$
\left\langle\gamma f\left(x^{\prime \prime}\right)-A x^{\prime \prime}, J_{\varphi}\left(v-x^{*}\right)\right\rangle \leq 0, \quad \forall v \in \operatorname{Fix}(\mathcal{S})
$$

Proof By the condition $\lim _{n \rightarrow \infty} \alpha_{n}=0$, we may assume, with no loss of generality, that $\alpha_{n} \leq \varphi(1)\|A\|^{-1}$ for all $n \in \mathbb{N}$. By Lemma 2.2, we have $\left\|I-\alpha_{n} A\right\| \leq \varphi(1)\left(1-\alpha_{n} \bar{\gamma}\right)$. First, we show that $\left\{x_{n}\right\}$ is bounded. Take $p \in \operatorname{Fix}(\mathcal{S})$ and $0<\epsilon<\varphi(1) \bar{\gamma}-\gamma \alpha$.

Since $\lim _{n \rightarrow \infty} \frac{\left(\frac{1}{t_{n}} \int_{0}^{t_{n}} L_{s} d s\right)-1}{\alpha_{n}}=0$ implies $\varphi(1)\left(1-\alpha_{n} \bar{\gamma}\right)\left[\left(\frac{1}{t_{n}} \int_{0}^{t_{n}} L_{s} d s\right)-1\right] \leq \epsilon \alpha_{n}$ for sufficiently large $n \geq 1$. Then from (4.1), we get that

$$
\begin{aligned}
\left\|x_{n+1}-p\right\| & =\left\|\alpha_{n}\left(\gamma f\left(x_{n}\right)-A p\right)+\left(I-\alpha_{n} A\right)\left(\frac{1}{t_{n}} \int_{0}^{t_{n}} T(s) x_{n} d s-p\right)\right\| \\
& \leq \alpha_{n}\left\|\gamma f\left(x_{n}\right)-A p\right\|+\varphi(1)\left(1-\alpha_{n} \bar{\gamma}\right)\left\|\frac{1}{t_{n}} \int_{0}^{t_{n}} T(s) x_{n} d s-p\right\|
\end{aligned}
$$




$$
\begin{aligned}
\leq & \alpha_{n} \gamma\left\|f\left(x_{n}\right)-f(p)\right\|+\alpha_{n}\|\gamma f(p)-A p\| \\
& +\varphi(1)\left(1-\alpha_{n} \bar{\gamma}\right)\left(\frac{1}{t_{n}} \int_{0}^{t_{n}} L_{s} d s\right)\left\|x_{n}-p\right\| \\
\leq & {\left[1-(\varphi(1) \bar{\gamma}-\gamma \alpha) \alpha_{n}+\varphi(1)\left(1-\alpha_{n} \bar{\gamma}\right)\left[\left(\frac{1}{t_{n}} \int_{0}^{t_{n}} L_{s} d s\right)-1\right]\right]\left\|x_{n}-p\right\| } \\
& +\alpha_{n}\|\gamma f(p)-A p\| \\
\leq & \left(1-(\varphi(1) \bar{\gamma}-\gamma \alpha-\epsilon) \alpha_{n}\right)\left\|x_{n}-p\right\|+\alpha_{n}\|\gamma f(p)-A p\| \\
= & \left(1-(\varphi(1) \bar{\gamma}-\gamma \alpha-\epsilon) \alpha_{n}\right)\left\|x_{n}-p\right\|+(\varphi(1) \bar{\gamma}-\gamma \alpha-\epsilon) \alpha_{n} \frac{\|\gamma f(p)-A p\|}{\varphi(1) \bar{\gamma}-\gamma \alpha-\epsilon} .
\end{aligned}
$$

By induction, we have

$$
\left\|x_{n}-p\right\| \leq \max \left\{\left\|x_{1}-p\right\|, \frac{\|\gamma f(p)-A p\|}{\varphi(1) \bar{\gamma}-\gamma \alpha-\epsilon}\right\}, \quad \forall n \geq 1
$$

Hence, $\left\{x_{n}\right\}$ is bounded, so are $\left\{f\left(x_{n}\right)\right\}$ and $\left\{A\left(\frac{1}{t_{n}} \int_{0}^{t_{n}} T(s) x_{n} d s\right)\right\}$.

Next, we show that $\left\|x_{n}-T(h) x_{n}\right\| \longrightarrow 0$ as $n \longrightarrow \infty$. From (4.1), we note that

$$
\left\|x_{n+1}-\frac{1}{t_{n}} \int_{0}^{t_{n}} T(s) x_{n} d s\right\|=\alpha_{n}\left\|\gamma f\left(x_{n}\right)-A\left(\frac{1}{t_{n}} \int_{0}^{t_{n}} T(s) x_{n} d s\right)\right\| .
$$

By the condition $(\mathrm{C} 1)$, we obtain

$$
\lim _{n \rightarrow \infty}\left\|x_{n+1}-\frac{1}{t_{n}} \int_{0}^{t_{n}} T(s) x_{n} d s\right\|=0
$$

For all $h \geq 0$, we note that

$$
\begin{aligned}
\left\|x_{n+1}-T(h) x_{n+1}\right\| \leq & \left\|x_{n+1}-\frac{1}{t_{n}} \int_{0}^{t_{n}} T(s) x_{n} d s\right\| \\
& +\left\|\frac{1}{t_{n}} \int_{0}^{t_{n}} T(s) x_{n} d s-T(h)\left(\frac{1}{t_{n}} \int_{0}^{t_{n}} T(s) x_{n} d s\right)\right\| \\
& +\left\|T(h)\left(\frac{1}{t_{n}} \int_{0}^{t_{n}} T(s) x_{n} d s\right)-T(h) x_{n+1}\right\| \\
\leq & \left\|x_{n+1}-\frac{1}{t_{n}} \int_{0}^{t_{n}} T(s) x_{n} d s\right\| \\
& +\left\|\frac{1}{t_{n}} \int_{0}^{t_{n}} T(s) x_{n} d s-T(h)\left(\frac{1}{t_{n}} \int_{0}^{t_{n}} T(s) x_{n} d s\right)\right\| \\
& +L_{h}\left\|x_{n+1}-\frac{1}{t_{n}} \int_{0}^{t_{n}} T(s) x_{n} d s\right\| .
\end{aligned}
$$

By Lemma 2.4 and (4.3), we obtain $\lim _{n \rightarrow \infty}\left\|x_{n+1}-T(h) x_{n+1}\right\|=0$ and hence

$$
\lim _{n \rightarrow \infty}\left\|x_{n}-T(h) x_{n}\right\|=0 \quad \text { for all } h \geq 0 .
$$


Next, we show that

$$
\limsup _{n \rightarrow \infty}\left\langle\gamma f\left(x^{*}\right)-A x^{*}, J_{\varphi}\left(x_{n}-x^{*}\right)\right\rangle \leq 0 .
$$

Let $\left\{x_{n_{j}}\right\}$ be a subsequence of $\left\{x_{n}\right\}$ such that

$$
\lim _{j \rightarrow \infty}\left\langle\gamma f\left(x^{*}\right)-A x^{*}, J_{\varphi}\left(x_{n_{j}}-x^{*}\right)\right\rangle=\limsup _{n \rightarrow \infty}\left\langle\gamma f\left(x^{*}\right)-A x^{*}, J_{\varphi}\left(x_{n}-x^{*}\right)\right\rangle .
$$

By reflexivity of $X$ and boundedness of $\left\{x_{n}\right\}$, there exists a weakly convergent subsequence $\left\{x_{n_{j}}\right\}$ of $\left\{x_{n}\right\}$ such that $x_{n_{j}} \rightarrow v \in X$ as $j \rightarrow \infty$. Since $J_{\varphi}$ is weakly continuous, we have by Lemma 2.1 that

$$
\limsup _{j \rightarrow \infty} \Phi\left(\left\|x_{n_{j}}-x\right\|\right)=\underset{j \rightarrow \infty}{\limsup } \Phi\left(\left\|x_{n_{j}}-v\right\|\right)+\Phi(\|x-v\|) \quad \text { for all } x \in X
$$

Let $H(x)=\limsup _{j \rightarrow \infty} \Phi\left(\left\|x_{n_{j}}-x\right\|\right)$ for all $x \in X$. It follows that

$$
H(x)=H(v)+\Phi(\|x-v\|) \quad \text { for all } x \in X
$$

Since $\Phi$ is continuous and $\lim _{h \rightarrow \infty} L_{h}=1$, it follows from (4.4) that

$$
\begin{aligned}
H\left(\lim _{h \rightarrow \infty} T(h) v\right) & =\lim _{h \rightarrow \infty} H(T(h) v) \\
& =\lim _{h \rightarrow \infty} \limsup _{j \rightarrow \infty} \Phi\left(\left\|x_{n_{j}}-T(h) v\right\|\right) \\
& =\lim _{h \rightarrow \infty} \limsup _{j \rightarrow \infty} \Phi\left(\left\|T(h) x_{n_{j}}-T(h) v\right\|\right) \\
& \leq \lim _{h \rightarrow \infty} \limsup _{j \rightarrow \infty} \Phi\left(L_{h}\left\|x_{n_{j}}-v\right\|\right) \\
& =\limsup _{j \rightarrow \infty} \Phi\left(\left\|x_{n_{j}}-v\right\|\right) \\
& =H(\tilde{x}) .
\end{aligned}
$$

On the other hand, we note that

$$
\begin{aligned}
H\left(\lim _{h \rightarrow \infty} T(h) v\right) & =\lim _{h \rightarrow \infty} \limsup _{j \rightarrow \infty} \Phi\left(\left\|x_{n_{j}}-v\right\|\right)+\lim _{h \rightarrow \infty} \Phi(\|T(h) v-v\|) \\
& =\limsup _{j \rightarrow \infty} \Phi\left(\left\|x_{n_{j}}-v\right\|\right)+\Phi\left(\lim _{h \rightarrow \infty}\|T(h) v-v\|\right) .
\end{aligned}
$$

Combining (4.5) and (4.6), we obtain $\Phi\left(\lim _{h \rightarrow \infty}\|T(h) v-v\|\right) \leq 0$. The property of $\Phi$ implies that $\lim _{h \rightarrow \infty} T(h) v=v$. In fact, since $T(t+h) x=T(t) T(h) x$ for all $x \in X$ and $t \geq 0$, then we have

$$
v=\lim _{h \rightarrow \infty} T(h) v=\lim _{h \rightarrow \infty} T(h+t) v=\lim _{h \rightarrow \infty} T(h) T(t) v=T(t) \lim _{h \rightarrow \infty} T(h) v=T(t) v
$$


for all $t \geq 0$. Hence, $v \in \operatorname{Fix}(\mathcal{S})$. Since $J_{\varphi}$ is single-valued and weakly continuous, we obtain that

$$
\begin{aligned}
\limsup _{n \rightarrow \infty}\left\langle\gamma f\left(x^{*}\right)-A x^{*}, J_{\varphi}\left(x_{n}-x^{*}\right)\right\rangle & =\lim _{j \rightarrow \infty}\left\langle\gamma f\left(x^{*}\right)-A x^{*}, J_{\varphi}\left(x_{n_{j}}-x^{*}\right)\right\rangle \\
& =\left\langle\gamma f\left(x^{*}\right)-A x^{*}, J_{\varphi}\left(v-x^{*}\right)\right\rangle \leq 0 .
\end{aligned}
$$

Finally, we show that $x_{n} \longrightarrow x^{*}$ as $n \longrightarrow \infty$. Now, from Lemma 2.1, we have

$$
\begin{aligned}
\Phi( & \left.\left\|x_{n+1}-x^{*}\right\|\right) \\
= & \Phi\left(\left\|\alpha_{n}\left(\gamma f\left(x_{n}\right)-A x^{*}\right)+\left(I-\alpha_{n} A\right)\left(\frac{1}{t_{n}} \int_{0}^{t_{n}} T(s) x_{n} d s-x^{*}\right)\right\|\right) \\
= & \Phi\left(\| \alpha_{n} \gamma\left(f\left(x_{n}\right)-f\left(x^{*}\right)\right)+\alpha_{n}\left(\gamma f\left(x^{*}\right)-A x^{*}\right)\right. \\
& \left.+\left(I-\alpha_{n} A\right)\left(\frac{1}{t_{n}} \int_{0}^{t_{n}} T(s) x_{n} d s-x^{*}\right) \|\right) \\
\leq & \Phi\left(\left\|\alpha_{n} \gamma\left(f\left(x_{n}\right)-f\left(x^{*}\right)\right)+\left(I-\alpha_{n} A\right)\left(\frac{1}{t_{n}} \int_{0}^{t_{n}} T(s) x_{n} d s-x^{*}\right)\right\|\right) \\
& +\alpha_{n}\left\langle\gamma f\left(x^{*}\right)-A x^{*}, J_{\varphi}\left(x_{n+1}-x^{*}\right)\right\rangle \\
\leq & \Phi\left(\left\{1-(\varphi(1) \bar{\gamma}-\gamma \alpha) \alpha_{n}+\varphi(1)\left(1-\alpha_{n} \bar{\gamma}\right)\left[\left(\frac{1}{t_{n}} \int_{0}^{t_{n}} L_{s} d s\right)-1\right]\right\}\left\|x_{n}-x^{*}\right\|\right) \\
& +\alpha_{n}\left\langle\gamma f\left(x^{*}\right)-A x^{*}, J_{\varphi}\left(x_{n+1}-x^{*}\right)\right\rangle \\
\leq & \left(1-(\varphi(1) \bar{\gamma}-\gamma \alpha) \alpha_{n}\right) \Phi\left(\left\|x_{n}-x^{*}\right\|\right) \\
& +\varphi(1)\left(1-\alpha_{n} \bar{\gamma}\right)\left[\left(\frac{1}{t_{n}} \int_{0}^{t_{n}} L_{s} d s\right)-1\right] \Phi\left(\left\|x_{n}-x^{*}\right\|\right) \\
& +\alpha_{n}\left\langle\gamma f\left(x^{*}\right)-A x^{*}, J_{\varphi}\left(x_{n+1}-x^{*}\right)\right\rangle \\
\leq & \left(1-(\varphi(1) \bar{\gamma}-\gamma \alpha) \alpha_{n}\right) \Phi\left(\left\|x_{n}-x^{*}\right\|\right) \\
& +\varphi(1)\left(1-\alpha_{n} \bar{\gamma}\right)\left[\left(\frac{1}{t_{n}} \int_{0}^{t_{n}} L_{s} d s\right)-1\right] M+\alpha_{n}\left\langle\gamma f\left(x^{*}\right)-A x^{*}, J_{\varphi}\left(x_{n+1}-x^{*}\right)\right\rangle,
\end{aligned}
$$

where $M=\sup _{n \geq 1}\left\{\Phi\left(\left\|x_{n}-x^{*}\right\|\right)\right\}$. Put $\sigma_{n}:=(\varphi(1) \bar{\gamma}-\gamma \alpha) \alpha_{n}$ and

$$
\delta_{n}:=\varphi(1)\left(1-\alpha_{n} \bar{\gamma}\right)\left[\left(\frac{1}{t_{n}} \int_{0}^{t_{n}} L_{s} d s\right)-1\right] M+\alpha_{n}\left\langle\gamma f\left(x^{*}\right)-A x^{*}, J_{\varphi}\left(x_{n+1}-x^{*}\right)\right\rangle .
$$

Then (4.8) reduces to formula

$$
\Phi\left(\left\|x_{n+1}-x^{*}\right\|\right) \leq\left(1-\sigma_{n}\right) \Phi\left(\left\|x_{n}-x^{*}\right\|\right)+\delta_{n} .
$$

It follows from the conditions (C1), (C2) and (4.7) that $\sum_{n=1}^{\infty} \sigma_{n}=\infty$ and

$$
\begin{aligned}
\limsup _{n \rightarrow \infty} \frac{\delta_{n}}{\sigma_{n}}= & \limsup _{n \rightarrow \infty} \frac{1}{\varphi(1) \bar{\gamma}-\gamma \alpha}\left[\frac{\varphi(1)\left(1-\alpha_{n} \bar{\gamma}\right)\left[\left(\frac{1}{t_{n}} \int_{0}^{t_{n}} L_{s} d s\right)-1\right]}{\alpha_{n}} M\right. \\
& \left.+\left\langle\gamma f\left(x^{*}\right)-A x^{*}, J_{\varphi}\left(x_{n+1}-x^{*}\right)\right\rangle\right] \leq 0 .
\end{aligned}
$$


Hence, by Lemma 2.5 , we obtain that $\Phi\left(\left\|x_{n+1}-x^{*}\right\|\right) \longrightarrow 0$ as $n \longrightarrow \infty$. The property of $\Phi$ implies that $x_{n} \longrightarrow x^{*}$ as $n \longrightarrow \infty$. This proof is complete.

Applications 4.2 Let $X$ be a uniformly convex Banach space which admits a weakly continuous duality mapping. Let $L(X)$ be the space of all bounded linear operators on $X$. For $\Psi \in L(X)$, define $\mathcal{S}:=\left\{T(t): t \in \mathbb{R}^{+}\right\}$of bounded linear operators by using the following exponential expression:

$$
T(t)=e^{-t \Psi}:=\sum_{k=0}^{\infty} \frac{(-1)^{k}}{k !} t^{k} \Psi^{k} .
$$

Then, clearly, the family $\mathcal{S}:=\left\{T(t): t \in \mathbb{R}^{+}\right\}$satisfies the semigroup properties. Moreover, this family forms a one-parameter semigroup of self-mappings of $X$ because $e^{t \Psi}=$ $\left[e^{-t \Psi}\right]^{-1}: X \rightarrow X$ exists for each $t \in \mathbb{R}^{+}$.

Next, the following example shows that all conditions of Theorem 4.1 are satisfied.

Example 4.3 For instance, let $\alpha_{n}=\frac{1}{n}, t_{n}=n^{2}$ and $L_{t}=1+\frac{1}{t+1}$. Then, clearly, the sequences $\left\{\alpha_{n}\right\},\left\{t_{n}\right\}$ and $\left\{L_{t}\right\}$ satisfy our assumptions and the condition (C1) in Theorem 4.1. We show that the condition (C2) is achieved. Indeed, we have

$$
\begin{aligned}
\frac{\frac{1}{t_{n}} \int_{0}^{t_{n}} L_{s} d s-1}{\alpha_{n}} & =\frac{\frac{1}{n^{2}} \int_{0}^{n^{2}}\left(1+\frac{1}{s+1}\right) d s-1}{1 / n} \\
& =n\left\{\frac{1}{n^{2}}\left(s+\left.\ln (s+1)\right|_{0} ^{n^{2}}\right)-1\right\} \\
& =n\left\{\frac{1}{n^{2}}\left(n^{2}+\ln \left(n^{2}+1\right)\right)-1\right\} \\
& =\frac{\ln \left(n^{2}+1\right)}{n} \longrightarrow 0, \quad \text { as } n \rightarrow \infty .
\end{aligned}
$$

Furthermore, if we take $\Psi \in L(X)$ such that $\|T(t)\| \leq 1+\frac{1}{t+1}$ and $\operatorname{Fix}(\mathcal{S}) \neq \emptyset$ (see, e.g., p.160 of [30]) then the sequence $\left\{x_{n}\right\}$ defined by (4.1) converges strongly to $x^{*} \in \operatorname{Fix}(\mathcal{S})$.

Remark 4.4 Theorem 4.1 extends and generalizes Theorem 3.5 of Zegeye et al. [7], Theorem 3.2 of Chen and Song [23] and Theorem 3.2 of Li et al. [22] in the following respects:

(1) Theorem 4.1 generalizes Theorem 3.5 of Zegeye et al. [7] to the viscosity iterative method in a different Banach space which admits a weakly continuous duality mapping.

(2) Theorem 4.1 improves Theorem 3.5 of Zegeye et al. [7] in the sense that our theorem is applicable in a uniformly convex Banach space without the requirement that $\mathcal{S}=\{T(t)$ : $\left.t \in \mathbb{R}^{+}\right\}$is almost uniformly asymptotically regular.

(3) Theorem 4.1 extends Theorem 3.2 of Chen and Song [23] from a class of strongly continuous semigroups of nonexpansive mappings to a more general class of strongly continuous semigroups of asymptotically nonexpansive mappings.

(4) Theorem 4.1 includes Theorem 3.2 of Li et al. [22] as a special case.

If $\mathcal{S}=\left\{T(t): t \in \mathbb{R}^{+}\right\}$is a strongly continuous semigroup of nonexpansive mappings, we have $L_{t} \equiv 1$ and then Theorem 4.1 is reduced to the following result. 
Corollary 4.5 Let X be a uniformly convex Banach space which admits a weakly continuous duality mapping $J_{\varphi}$ with a gauge $\varphi$ such that $\varphi$ is invariant on $[0,1]$. Let $\mathcal{S}=\{T(t): t \in$ $\left.\mathbb{R}^{+}\right\}$be a strongly continuous semigroup of nonexpansive mappings from $X$ into itself such that $\operatorname{Fix}(\mathcal{S}) \neq \emptyset$. Let $f: X \rightarrow X$ be a contraction mapping with a constant $\alpha \in(0,1)$ and $A: X \rightarrow X$ be a strongly positive linear bounded operator with a constant $\bar{\gamma} \in(0,1)$ such that $0<\gamma<\frac{\bar{\gamma} \varphi(1)}{\alpha}$. For given $x_{1} \in C$, let $\left\{x_{n}\right\}$ be a sequence defined by

$$
x_{n+1}=\alpha_{n} \gamma f\left(x_{n}\right)+\left(I-\alpha_{n} A\right) \frac{1}{t_{n}} \int_{0}^{t_{n}} T(s) x_{n} d s, \quad \forall n \geq 1,
$$

where $\left\{\alpha_{n}\right\}$ is a sequence in $(0,1)$ such that $\lim _{n \rightarrow \infty} \alpha_{n}=0$ and $\sum_{n=1}^{\infty} \alpha_{n}=\infty$, and $\left\{t_{n}\right\}$ is a positive real divergent sequence. Then the sequence $\left\{x_{n}\right\}$ defined by (4.9) converges strongly to $x^{*} \in \operatorname{Fix}(\mathcal{S})$, where $x^{*}$ is the unique solution of the variational inequality

$$
\left\langle\gamma f\left(x^{*}\right)-A x^{*}, J_{\varphi}\left(v-x^{*}\right)\right\rangle \leq 0, \quad \forall v \in \operatorname{Fix}(\mathcal{S}) .
$$

Corollary 4.6 (Li et al. [22, Theorem 3.2]) Let $H$ be a real Hilbert space and $C$ be a nonempty closed convex subset of $X$ such that $C \pm C \subset C$. Let $\mathcal{S}=\left\{T(t): t \in \mathbb{R}^{+}\right\}$be a strongly continuous semigroup of nonexpansive mappings from $C$ into itself such that $\operatorname{Fix}(\mathcal{S}) \neq \emptyset$. Let $f: C \longrightarrow C$ be a contraction mapping with a constant $\alpha \in(0,1)$ and $A: C \rightarrow C$ be a strongly positive linear bounded operator with a constant $\bar{\gamma} \in(0,1)$ such that $0<\gamma<\frac{\bar{\gamma}}{\alpha}$. For given $x_{1} \in C$, let $\left\{x_{n}\right\}$ be a sequence defined by

$$
x_{n+1}=\alpha_{n} \gamma f\left(x_{n}\right)+\left(I-\alpha_{n} A\right) \frac{1}{t_{n}} \int_{0}^{t_{n}} T(s) x_{n} d s, \quad \forall n \geq 1,
$$

where $\left\{\alpha_{n}\right\}$ is a sequence in $(0,1)$ such that $\lim _{n \rightarrow \infty} \alpha_{n}=0$ and $\sum_{n=1}^{\infty} \alpha_{n}=\infty$, and $\left\{t_{n}\right\}$ is a positive real divergent sequence. Then the sequence $\left\{x_{n}\right\}$ defined by (4.11) converges strongly to $x^{*} \in \operatorname{Fix}(\mathcal{S})$, where $x^{*}$ is the unique solution of the variational inequality

$$
\left\langle\gamma f\left(x^{*}\right)-A x^{*}, v-x^{*}\right\rangle \leq 0, \quad \forall v \in \operatorname{Fix}(\mathcal{S})
$$

\section{Competing interests}

The authors declare that they have no competing interests.

\section{Authors' contributions}

All authors contributed equally and significantly in writing this article. All authors read and approved the final manuscript.

\section{Acknowledgements}

The authors were supported by the Higher Education Research Promotion and National Research University Project of Thailand, Office of the Higher Education Commission (NRU-CSEC No. 55000613)

\section{Received: 28 July 2012 Accepted: 2 October 2012 Published: 17 October 2012}

References

1. Goebel, K, Kirk, WA: A fixed point theorem for asymptotically nonexpansive mappings. Proc. Am. Math. Soc. 35, 171-174 (1972)

2. Lau, AT-M: Amenability and fixed point property for semigroup of nonexpansive mapping. In: Thera, MA, Baillon, JB (eds.) Fixed Point Theory and Applications. Pitman Res. Notes Math. Ser., vol. 252, pp. 303-313. Longman, Harlow (1991)

3. Lau, AT-M: Invariant means and fixed point properties of semigroup of nonexpansive mappings. Taiwan. J. Math. 12 1525-1542 (2008) 
4. Lau, AT-M, Miyake, H, Takahashi, W: Approximation of fixed points for amenable semigroups of nonexpansive mappings in Banach spaces. Nonlinear Anal. TMA 67, 1211-1225 (2007)

5. Aleyner, A, Censor, Y: Best approximation to common fixed points of a semigroup of nonexpansive operators. J. Nonlinear Convex Anal. 6, 137-151 (2005)

6. Cholamjiak, P, Suantai, S: Viscosity approximation methods for a nonexpansive semigroup in Banach spaces with gauge functions. J. Glob. Optim. 54, 185-197 (2012)

7. Zegeye, H, Shahzad, N, Daman, OA: Strong convergence theorems for a semigroup of asymptotically nonexpansive mappings. Math. Comput. Model. 54, 2077-2086 (2011)

8. Zegeye, $\mathrm{H}$, Shahzad, N: Convergence theorems for strongly continuous semi-groups of asymptotically nonexpansive mappings. Nonlinear Anal. 71, 2308-2315 (2009)

9. Zegeye, H, Shahzad, N: Strong convergence theorems for continuous semigroups of asymptotically nonexpansive mappings. Numer. Funct. Anal. Optim. 30(7), 833-848 (2009)

10. Sunthrayuth, P, Kumam, P: Approximating solutions of variational inequalities on the sets of common fixed points for a semigroup of asymptotically nonexpansive mappings in Banach spaces. Math. Sci. 6, 20 (2012)

11. Bynum, WL: Normal structure coefficients for Banach spaces. Pac. J. Math. 86, 427-436 (2001)

12. Byrne, $C:$ A unified treatment of some iterative algorithms in signal processing and image reconstruction. Inverse Probl. 20, 103-120 (2004)

13. Podilchuk, Cl, Mammone, RJ: Image recovery by convex projections using a least-squares constraint. J. Opt. Soc. Am. A 7, 517-521 (1990)

14. Sezan, Ml, Stark, H: Applications of convex projection theory to image recovery in tomography and related areas. In: Stark, H (ed.) Image Recovery Theory and Applications, pp. 415-462. Academic Press, Orlando (1987)

15. Youla, D: Mathematical theory of image restoration by the method of convex projections. In: Stark, H (ed.) Image Recovery Theory and Applications, pp. 29-77. Academic Press, Orlando (1987)

16. Youla, D: On deterministic convergence of iterations of relaxed projection operators. J. Vis. Commun. Image Represent. 1, 12-20 (1990)

17. Deutsch, F, Yamada, I: Minimizing certain convex functions over the intersection of the fixed point sets of nonexpansive mappings. Numer. Funct. Anal. Optim. 19, 33-56 (1998)

18. Xu, HK: An iterative approach to quadratic optimization. J. Optim. Theory Appl. 116, 659-678 (2003)

19. Xu, HK: Viscosity approximation methods for nonexpansive mappings. J. Math. Anal. Appl. 298, 279-291 (2004)

20. Moudafi, A: Viscosity approximation methods for fixed-points problems. J. Math. Anal. Appl. 241, 46-55 (2000)

21. Marino, G, Xu, HK: A general iterative for nonexpansive mapping in Hilbert spaces. J. Math. Anal. Appl. 318, 43-52 (2006)

22. Li, S, Li, L, Su, Y: General iterative methods for one-parameter nonexpansive semigroup in Hilbert space. Nonlinear Anal., Theory Methods Appl. 70, 3065-3071 (2009)

23. Chen, R, Song, Y: Convergence to common fixed point of nonexpansive semigroup. J. Comput. Appl. Math. 200 566-575 (2007)

24. Takahashi, W: Nonlinear Functional Analysis. Yokohama Publishers, Yokohama (2000)

25. Browder, FE: Convergence theorems for sequences of nonlinear operators in Banach spaces. Math. Z. 100, 201-225 (1967)

26. Wangkeeree, R, Petrot, N, Wangkeeree, R: The general iterative methods for nonexpansive mappings in Banach spaces. J. Glob. Optim. 51, 27-46 (2011)

27. Cai, G, Hu, CS: Strong convergence theorems of a general iterative process for a finite family of $\boldsymbol{\lambda}_{i}$-strict pseudo-contraction in q-uniformly smooth Banach spaces. Comput. Math. Appl. 59, 49-160 (2010)

28. Lim, TC, Xu, HK: Fixed point theorems for asymptotically nonexpansive mappings. Nonlinear Anal., Theory Methods Appl. 22, 1345-1355 (1994)

29. Xu, HK: Iterative algorithms for nonlinear operators. J. Lond. Math. Soc. 66(1), 240-256 (2002)

30. Reich, S, Shoiklet, D: Nonlinear Semigroups, Fixed Points and Geometry of Domains in Banach Spaces. Imperial Collage press, London (2005)

doi:10.1186/1687-1812-2012-177

Cite this article as: Sunthrayuth and Kumam: Fixed point solutions of variational inequalities for a semigroup of asymptotically nonexpansive mappings in Banach spaces. Fixed Point Theory and Applications 2012 2012:177.

\section{Submit your manuscript to a SpringerOpen ${ }^{\ominus}$ journal and benefit from:}

- Convenient online submission

Rigorous peer review

- Immediate publication on acceptance

- Open access: articles freely available online

- High visibility within the field

- Retaining the copyright to your article

Submit your next manuscript at $\gg$ springeropen.com 